\title{
Effect of Zr on solidification and microstructure of a Ni-based superalloy with high $\mathrm{Al}$ and Ti
} contents

\author{
*Guang-di Zhao', Xi-min Zang', Fang Liu², Wei-wei Zhang ${ }^{2}$, Shuo Gao', Xue Li', and Jing Guo' \\ 1. School of Materials and Metallurgy, University of Science and Technology Liaoning, Anshan 114051, Liaoning, China \\ 2. Institute of Metal Research, Chinese Academy of Sciences, Shenyang 110016, China
}

\begin{abstract}
The total content of $\mathrm{Al}$ and $\mathrm{Ti}$ in advanced Ni-based wrought superalloys is up to 7.5 wt.\%, which makes it easier to form harmful nonequilibrium eutectic $\left(\gamma^{+} \gamma^{\prime}\right)$ and $\eta$ phase. It has been reported that the addition of certain amount of $\mathrm{Zr}$ can modify precipitation of the nonequilibrium phases obviously, but the mechanism is still controversial. The effect of $\mathrm{Zr}$ ranging from $<0.0006 \mathrm{wt} . \%$ to $0.150 \mathrm{wt} . \%$ on solidification behavior, segregation and microstructure of a Ni-based superalloy with high Al and Ti contents was investigated, eliminating the interferences of $C$ and B. Results show that increase in $Z r$ content significantly promotes the formation of eutectic $\left(\gamma^{+} \gamma^{\prime}\right), \eta$ and $Z r$-rich phase in the interdendritic region. Besides the Zr-rich phase, Zr dissolves slightly in the eutectic $\gamma^{\prime}$ and obviously in the $\eta$ phase. An interesting phenomenon is discovered that the $Z r$ addition significantly increases the area fraction of liquid pools and enlarges the forming range of $y$ dendrites, which suggests that $Z r$ markedly retards the solidification. $Z r$ affects the eutectic $\left(\gamma^{+} \gamma^{\prime}\right)$ and $\eta$ formation mainly due to the retard of solidification and dissolution of $\mathrm{Zr}$ in them. The retard of solidification obviously increases the residual liquid fraction and undercooling. $\mathrm{Zr}$ can serve as a forming element for the eutectic $\left(\gamma^{+} \gamma^{\prime}\right)$ and $\eta$ phase, and the obvious dissolution of $\mathrm{Zr}$ in $\eta$ phase significantly decreases the critical concentration of Ti for its precipitation.
\end{abstract}

Keywords: zirconium; Ni-based superalloy; solidification behavior; segregation

CLC numbers: TG132.3 3 Document code: A Article ID: 1672-6421(2022)01-017-10

\section{Introduction}

Ni-based wrought superalloys are key materials for aero-engines turbine disks, chiefly owing to their superior corrosion, fatigue and creep resistance at elevated temperatures ${ }^{[1,2]}$. To satisfy the demand that aero-engines continue to develop, the total amount of $\gamma^{\prime}$ (the main strengthening phase) forming elements $\mathrm{Al}$ and $\mathrm{Ti}$ in advanced alloys has reached $7.5 \mathrm{wt} . \%{ }^{[3,4]}$. However, the more the addition of $(\mathrm{Al}+\mathrm{Ti})$, the easier to form nonequilibrium eutectic $\left(\gamma+\gamma^{\prime}\right)$ and $\eta$ phase at the final solidification stage ${ }^{[5,6]}$. U720Li is a relatively advanced Ni-based superalloy containing high $(\mathrm{Al}+\mathrm{Ti})$ content ${ }^{[7,8]}$. It was found that the eutectic $\left(\gamma+\gamma^{\prime}\right)$ and $\eta$ phases were easy to become source of crack initiation sites during hot deformation of U720Li ingots ${ }^{[9]}$. Thus, these two phases must be eliminated by high temperature

\section{*Guang-di Zhao}

Male, born in 1989, Associate Professor, Ph.D. His research interests mainly focus on the solidification segregation and hot deformation behaviors of metals. To date, he has published 12 papers.

E-mail: gdzhao12s@alum.imr.ac.cn

Received: 2021-03-25; Accepted: 2021-07-27 homogenization before cogging. Since coarse eutectic $\left(\gamma+\gamma^{\prime}\right)$ and $\eta$ particles are very difficult to dissolve ${ }^{[10,11]}$, the homogenization time of high (Al+Ti) content Ni-based superalloys must be greatly extended which obviously increases the production cost ${ }^{[12]}$. Therefore, it is urgent to reduce formation of these nonequilibrium phases during solidification of such superalloys.

The formation of nonequilibrium solidification phases in Ni-based superalloys can be controlled by changing the preparation process, changing the cooling rate and microalloying. The size of nonequilibrium phases can be largely reduced by employing powder metallurgy (PM) route ${ }^{[1,13]}$. However, due to its long processing cycle and need for hot extrusion and isothermal forging, the PM route has some drawbacks ${ }^{[14]}$. For example, inclusions are easy to be introduced which has a negative impact on the fatigue performance of components. Besides, the cost of PM route is much higher than that of conventional cast and wrought route. Studies have shown that during solidification of Ni-based superalloys, the formation of coarse eutectic $\left(\gamma+\gamma^{\prime}\right)$ can be inhibited by raising cooling rates ${ }^{[15-17]}$. However, this method is only applicable to small cross-section ingots ${ }^{[18]}$. Minor elements $\mathrm{C}, \mathrm{B}$ and $\mathrm{Zr}$ are usually doped in Ni-based 
wrought superalloys for better mechanical properties ${ }^{[19-22]}$. Besides, they also have significant effects on solidification microstructures. For example, $\mathrm{C}$ addition obviously reduces eutectic $\left(\gamma+\gamma^{\prime}\right)$ formation ${ }^{[23-25]}$, while certain amounts of $\mathrm{B} / \mathrm{Zr}$ addition significantly increases its formation ${ }^{[5,22,26-28]}$. From the perspective of cost and applicability, reasonable controlling addition of these minor elements should be the most suitable method to reduce formation of the nonequilibrium phases.

Many investigations have discussed about how the $\mathrm{C}$ and $\mathrm{B}$ affect solidification microstructures of Ni-based superalloys ${ }^{[23-25,27-28]}$. Recently, the influencing mechanisms of $\mathrm{C}$ and B on the eutectic $\left(\gamma+\gamma^{\prime}\right)$ and $\eta$ precipitation in U720Li alloy were revealed on the base of previous studies ${ }^{[5,29]}$. While, only a few researchers have discussed about how $\mathrm{Zr}$ affects precipitation of the nonequilibrium phases in Ni-based superalloys, and the mechanism is still controversial. Zhou et al. ${ }^{[22]}$ proposed that $\mathrm{Zr}$ promoted eutectic $\left(\gamma+\gamma^{\prime}\right)$ precipitation in M951 alloy because its enrichment in residual liquid may hinder the diffusion of other elements and increase the segregation degree of eutectic forming elements. However, Qi et al. ${ }^{[30]}$ considered that $\mathrm{Zr}$ increased the eutectic $\left(\gamma+\gamma^{\prime}\right)$ precipitation during solidification of $\mathrm{K} 417 \mathrm{G}$ alloy mainly because the Zr-rich film formed at solid/liquid interfaces decreased the solidification rate of the alloy and reduced $\mathrm{Ti}$, $\mathrm{Al}$, Mo and $\mathrm{Cr}$ contents in dendrite cores. Thus, further study is needed to reveal the fundamental cause of $\mathrm{Zr}$ on precipitation of the nonequilibrium solidification phases. It should be noted that a $\mathrm{Zr}$ addition of $0-0.05 \mathrm{wt} . \%$ almost has no influence on the eutectic $\left(\gamma+\gamma^{\prime}\right)$ precipitation according to the reference ${ }^{[10]}$. This may be due to the fact that the experimental alloys in that study contain a certain amount of $\mathrm{C}^{[10]}$, and $\mathrm{Zr}$ can markedly segregate to $\mathrm{MC}$ carbides during solidification ${ }^{[22,31]}$. When the $\mathrm{Zr}$ content is relatively low, most $\mathrm{Zr}$ in residual liquid would be consumed by the formation of MC carbides before the eutectic $\left(\gamma+\gamma^{\prime}\right)$ precipitation, considering that the MC carbides form at an earlier solidification stage than eutectic $\left(\gamma+\gamma^{\prime}\right)$ in Ni-based superalloys ${ }^{[6,29]}$. Apparently, the existence of $C$ can cause interference to the effect of $\mathrm{Zr}$. Moreover, since minor B ( 0.01wt.\%) has significant influence on formation of the nonequilibrium phases, its existence may also interfere with the role of $\mathrm{Zr}$.

Therefore, this study aims to investigate the role of $\mathrm{Zr}$ in modifying solidification behavior and microstructure of a Nibased wrought superalloy containing high $\mathrm{Al}$ and $\mathrm{Ti}$ contents, eliminating the interferences of $\mathrm{C}$ and $\mathrm{B}$. How the $\mathrm{Zr}$ addition influences the solute segregation and solidification rate was revealed, and the mechanism by which $\mathrm{Zr}$ affects the eutectic $\left(\gamma+\gamma^{\prime}\right)$ and $\eta$ phase precipitation was discussed accordingly. The results can provide some guidance for controlling the doping of $\mathrm{Zr}$ in such superalloys.

\section{Experimental procedure}

A $19 \mathrm{~kg}$ master ingot was prepared in a vacuum induction melting (VIM) furnace according to the major elements in
U720Li alloy, and its chemical composition is shown in Table 1. Note that the master ingot is free of $\mathrm{C}$ and $\mathrm{B}$, and hence their interferences can be eliminated. The master ingot was cut into three pieces with almost the same weight, which were subsequently remelted in the VIM furnace to prepare three $5.0 \mathrm{~kg}$ ingots with the same pouring temperature of $1,420{ }^{\circ} \mathrm{C}$. One was directly poured into a cast iron mold, while the other two were doped with different amounts of pure $\mathrm{Zr}$ before pouring. Contents of $\mathrm{Zr}$ in the ingots were determined by inductively coupled plasma-atomic emission spectrometry (ICP-AES) to be $<0.0006 w t . \%$ (undoped alloy), 0.043wt.\% (middle-Zr alloy) and 0.150wt.\% (high-Zr alloy), respectively.

Table 1: Chemical composition of master alloy (wt.\%)

\begin{tabular}{ccccccc} 
Al & Ti & Cr & Co & Mo & W & Ni \\
\hline 2.48 & 4.99 & 15.99 & 15.02 & 2.98 & 1.17 & Bal. \\
\hline
\end{tabular}

The effect of $\mathrm{Zr}$ on solidification behavior was analyzed by differential thermal analysis (DTA). Cylindrical samples of $\Phi 3.5 \mathrm{~mm} \times 2 \mathrm{~mm}$ were cut from half radius of the above ingots. All surfaces of the samples were ground down to 400-grit $\mathrm{SiC}$ paper and ultrasonically cleaned. After drying, the samples were placed in a high-purity alumina crucible and tested in an argon atmosphere from $900{ }^{\circ} \mathrm{C}$ to $1,400{ }^{\circ} \mathrm{C}$. Both the heating rate and cooling rate were set to $10{ }^{\circ} \mathrm{C} \cdot \mathrm{min}^{-1}$.

Subsequently, the solidified DTA samples were polished mechanically and etched electrolytically in a solution of $13 \mathrm{~mL}$ $\mathrm{H}_{3} \mathrm{PO}_{4}+42 \mathrm{~mL} \mathrm{HNO}_{3}+43 \mathrm{~mL} \mathrm{H}_{2} \mathrm{SO}_{4}$ under DC $2 \mathrm{~V}$ for 3-5 s. Their solidification microstructures were observed under the optical microscopy (OM) and Zeiss-IGMA HD field emission scanning electron microscopy (FESEM). Chemical compositions of the nonequilibrium solidification phases and element distribution in the interdendritic region of high-Zr sample were examined by energy dispersive spectrometry (EDS) attached to the FESEM. Area fractions of the eutectic $\left(\gamma+\gamma^{\prime}\right)$ and $\eta$ phase were determined quantitatively using Image-Pro Plus 6.0 software, and their particle sizes were measured using the Nano Measurer 1.2 software. More than ten optical micrographs $(\times 100)$ were taken from each sample to obtain the average values. The area fractions of phases in superalloys can represent their volume fractions ${ }^{[32,33]}$.

Understanding the microstructure evolution and elemental segregation before the nonequilibrium phases formation is critical to study the influencing mechanism of $\mathrm{Zr}$ on these phases ${ }^{[5]}$. Thus, a high temperature quenching test was performed. Samples with dimensions of $8 \mathrm{~mm} \times 8 \mathrm{~mm} \times 8 \mathrm{~mm}$ were cut from half radius of the undoped alloy and high- $\mathrm{Zr}$ alloy ingots. All surfaces of these samples were ground down to 800-grit SiC paper. Then, they were manually covered with alumina sol and dried afterwards to avoid the oxygenation loss during thermal exposure at high temperatures. Subsequently, the samples were placed in an alumina crucible which was heated from room temperature to $1,400{ }^{\circ} \mathrm{C}$ at $10{ }^{\circ} \mathrm{C} \cdot \mathrm{min}^{-1}$ and soaked for $5 \mathrm{~min}$ in a tube furnace, then cooled to $1,250{ }^{\circ} \mathrm{C}$ at $10^{\circ} \mathrm{C} \cdot \mathrm{min}^{-1}$ and soaked for $3 \mathrm{~min}$, finally quenched in cold water. The 
as-quenched samples were deeply ground (about $3 \mathrm{~mm}$ were ground off), then polished and etched using the same method as the solidified DTA samples above. Then, the as-quenched microstructures were observed under the OM and SEM. The average area fraction of the liquid pools in the as-quenched microstructure was determined using the Image-Pro Plus 6.0 software. The average length and width of the liquid pools were determined using the Nano Measurer 1.2 software. At least five optical micrographs $(\times 100)$ taken from each sample were used for the measurements. The distribution of $\mathrm{Zr}$ in the high-Zr alloy as-quenched sample was analyzed by the EDS.

To clarify the effect of $\mathrm{Zr}$ on segregation behavior, compositions of the dendrite core, segregated region, eutectic $\left(\gamma+\gamma^{\prime}\right)$ and $\eta$ phase in solidified DTA samples and those of dendrite core and segregated region in as-quenched samples were determined by the EDS (rectangular region X-ray acquisition). Five measurements were used to calculate the average values.

\section{Results}

\subsection{Microstructures of solidified DTA samples}

The nonequilibrium solidification phases formed in U720Li alloy have been identified by the electron probe microanalyzer (EPMA) and transmission electron microscope (TEM) ${ }^{[34]}$. In this study, the solidification microstructures were analyzed on this basis. Figure 1 shows the dendritic structures of the solidified DTA samples with different $\mathrm{Zr}$ contents under OM. It is obvious that the $\mathrm{Zr}$ addition has no obvious influence on the secondary dendrite arm spacing (SDAS). Figure 2 shows the change of SDAS with Zr contents. Rosette-like eutectic $\left(\gamma+\gamma^{\prime}\right)$ and lath-like $\eta$ phase are observed in the interdendritic regions of all the samples [Figs. 1(d), (e) and (f)]. Quantitative statistics show that the area fraction [Fig. 3(a)], size [Fig. 3(b)] and number density (number of second particles per unit area) [Fig. 3(c)] of the eutectic $\left(\gamma+\gamma^{\prime}\right)$ and $\eta$ phase increase linearly
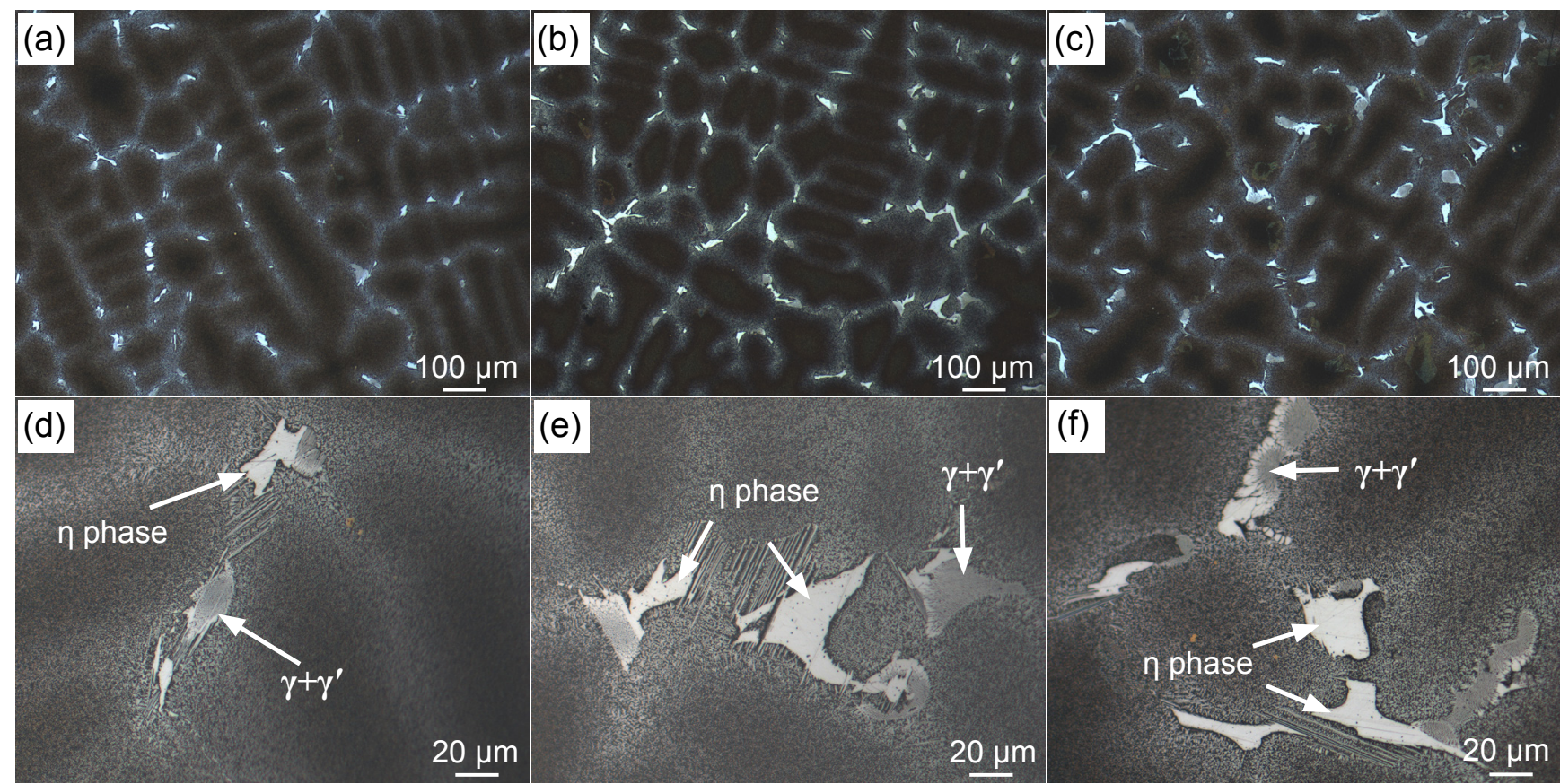

Fig. 1: OM images showing dendritic structures of solidified DTA samples: (a, c) undoped alloy with $<0.0006 \mathrm{wt} . \% \mathrm{Zr}$, (b, e) middle- $\mathrm{Zr}$ alloy with $0.043 \mathrm{wt} . \% \mathrm{Zr}$ and (c, f) high-Zr alloy with $0.150 \mathrm{wt} . \% \mathrm{Zr}$

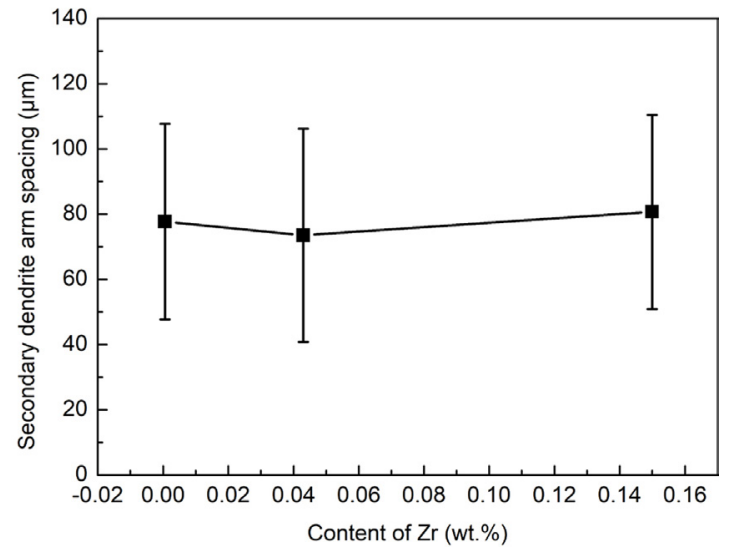

Fig. 2: Effect of $\mathrm{Zr}$ on secondary dendrite arm spacing of solidified DTA samples with increase in $\mathrm{Zr}$ addition. Besides, for each sample, the area fraction, size and number density of $\eta$ phase are obviously greater than those of eutectic $\left(\gamma+\gamma^{\prime}\right)$ (Fig. 3). Most notably, a $\mathrm{Zr}$ addition of $0.043 \mathrm{wt} . \%$ (lower than $0.05 \mathrm{wt} . \%$ ) increases eutectic $\left(\gamma+\gamma^{\prime}\right)$ precipitation, which is inconsistent with Ref. [10]. The most likely reason is the elimination of $\mathrm{C}$ interference.

Detailed microstructures of the solidified DTA samples were observed under SEM-BSE (back-scattered electron) as shown in Fig. 4. Besides the eutectic $\left(\gamma+\gamma^{\prime}\right)$ and $\eta$ phase, a honeycomb-like $\mathrm{Zr}$-rich phase attached to them was observed in the middle-Zr alloy and high-Zr alloy [Figs. 4(c)-(f)]. Based on the EDS analysis, $\mathrm{Ni}$ and $\mathrm{Zr}$ are the main constituent elements for the Zr-rich phase [Fig. 5(a), Point A in Fig. 4(e)], and it should be $\mathrm{Ni}_{5} \mathrm{Zr}$ according to previous study ${ }^{[34]}$. In 

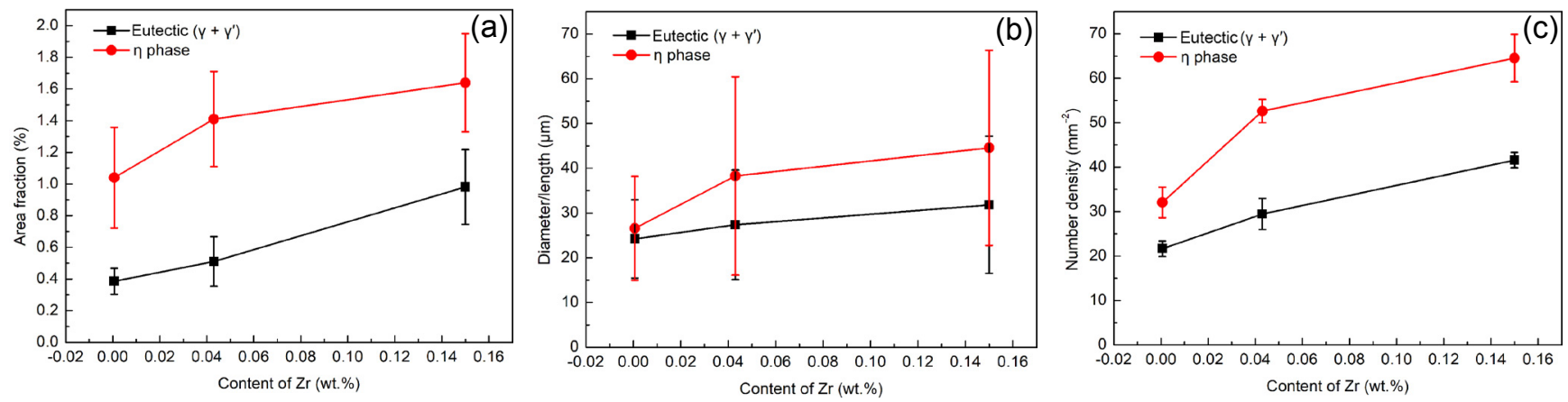

Fig. 3: Effect of Zr on area fractions (a), sizes (b) and number densities (c) of eutectic $\left(\gamma^{+} \gamma^{\prime}\right)$ and $\eta$ phase
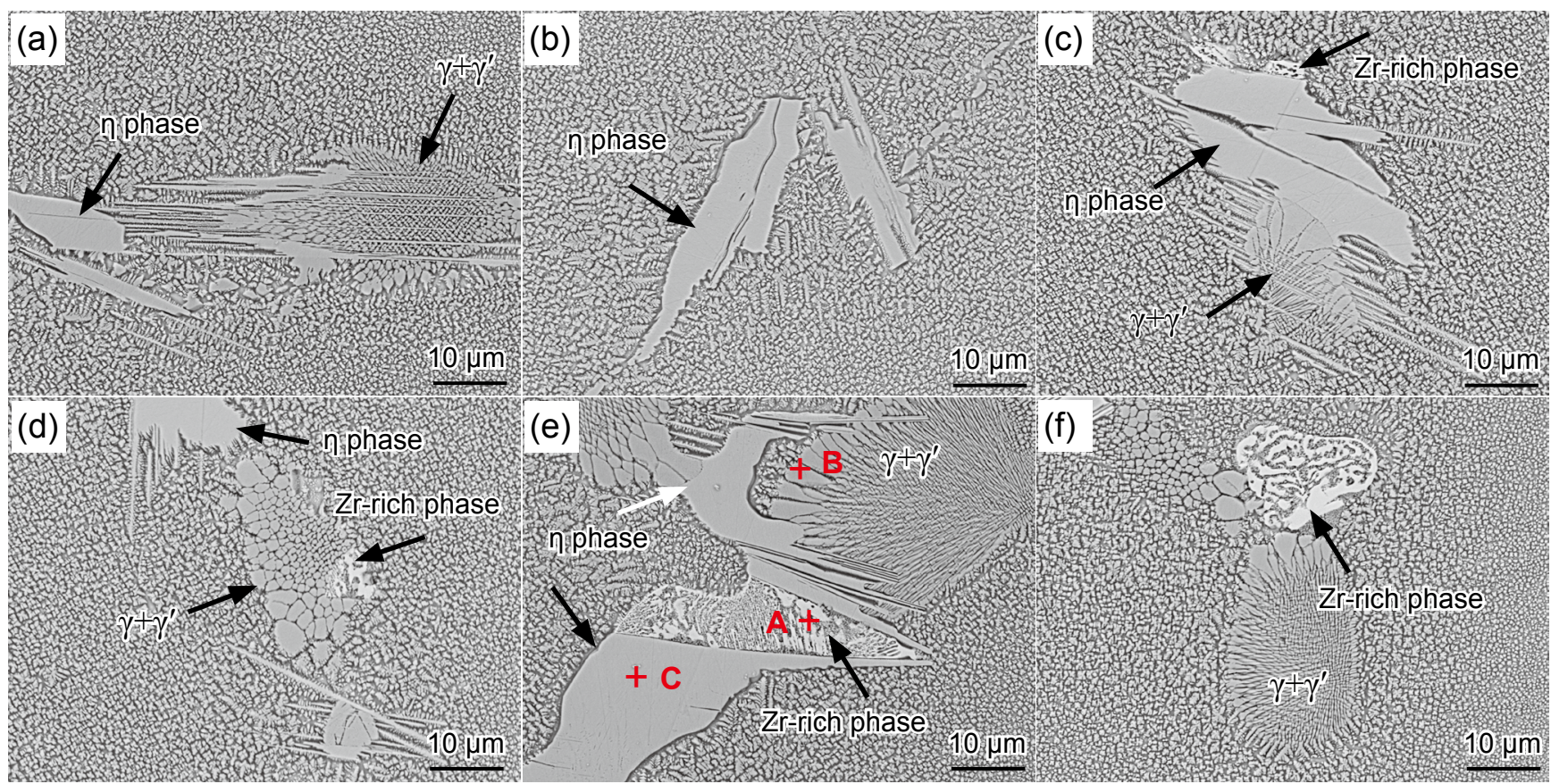

Fig. 4: Precipitates in interdendritic regions of solidified DTA samples: (a, b) undoped alloy with $<0.0006 w t . \% \mathrm{Zr}$; (c, d) middle-Zr alloy with $0.043 w t . \% \mathrm{Zr}$; and (e, f) high-Zr alloy with $0.150 \mathrm{wt} . \% \mathrm{Zr}$

addition, a small $\mathrm{Zr}$ peak appears in the EDS spectrum of eutectic $\gamma^{\prime}$ [Fig. 5(b), Point B in Fig. 4(e)] and a much larger Zr peak appears in that of $\eta$ phase [Fig. 5(c), Point C in Fig. 4(e)], which indicates that $\mathrm{Zr}$ can also segregate to these two phases and the degree of $\mathrm{Zr}$ segregation to $\eta$ phase is much greater.

In order to describe the element distribution (especially $\mathrm{Zr}$ ) between these nonequilibrium phases more intuitively, the EDS mapping was conducted in the interdendritic region of high-Zr alloy sample and the result is shown in Fig. 6. Clearly, the $\mathrm{Zr}$ is strongly enriched in the $\mathrm{Zr}$-rich phase and markedly dissolved in the $\eta$ phase, which is consistent with the EDS spectra in Fig. 5. The Ti is highly enriched in the eutectic $\left(\gamma+\gamma^{\prime}\right)$ and $\eta$ phase, but $\mathrm{Cr}$ is obviously depleted in them. The distributions of $\mathrm{Al}, \mathrm{Co}$ and Mo are relatively uniform.

\subsection{Solidification characteristic}

DTA cooling curves of the undoped, middle- $\mathrm{Zr}$ and high-Zr alloys are shown in Fig. 7. There are three exothermic peaks expressed as $\mathrm{P}-\mathrm{C} 1, \mathrm{P}-\mathrm{C} 2$ and $\mathrm{P}-\mathrm{C} 3$ on each cooling curve. Several research works have indicated that $\mathrm{P}-\mathrm{C} 1$ associates with the growth of $\gamma$ dendrites and P-C3 associates with the $\gamma^{\prime}$ precipitation ${ }^{[6,27,34]}$. However, it is difficult to figure out what the formation of P-C2 associates with. Our earlier studies have determined that in as-cast U720Li alloy, the melting points of $\mathrm{Ni}_{5} \mathrm{Zr}, \eta$ phase and eutectic $\left(\gamma+\gamma^{\prime}\right)$ are respectively in the ranges of $1,130-1,140{ }^{\circ} \mathrm{C}, 1,190-1,200{ }^{\circ} \mathrm{C}$ and $1,200-1,230{ }^{\circ} \mathrm{C}$ using the quenching method (soaking at elevated temperatures for 10 min before quenching in cold water) ${ }^{[11,34,35]}$. So, it can be inferred that the precipitation temperatures of $\eta$ phase and eutectic $\left(\gamma+\gamma^{\prime}\right)$ should be very close, but that of $\mathrm{Ni}_{5} \mathrm{Zr}$ is much lower. Chang et al. ${ }^{[6]}$ considered that the exothermic peaks of eutectic $\left(\gamma+\gamma^{\prime}\right)$ and $\eta$ formation in U720Li alloy overlap and cannot be distinguished. Above all, the P-C2 most likely associates with the formation of both eutectic $\left(\gamma+\gamma^{\prime}\right)$ and $\eta$ phase. Unfortunately, formation of the Zr-rich phase was not reflected on the DTA curves, which may be owing to the minor content of $\mathrm{Zr}$.

The initial, peak and final temperatures of exothermic peaks on the DTA cooling curves are summarized in Table 2. It is clear that the $\mathrm{Zr}$ addition has little influence on initial and peak temperatures of $\mathrm{P}-\mathrm{C} 1$, but slightly reduces the initial, peak and final temperatures of $\mathrm{P}-\mathrm{C} 2$. This means that $\mathrm{Zr}$ has no obvious effect on the nucleation of $\gamma$ dendrites, but 

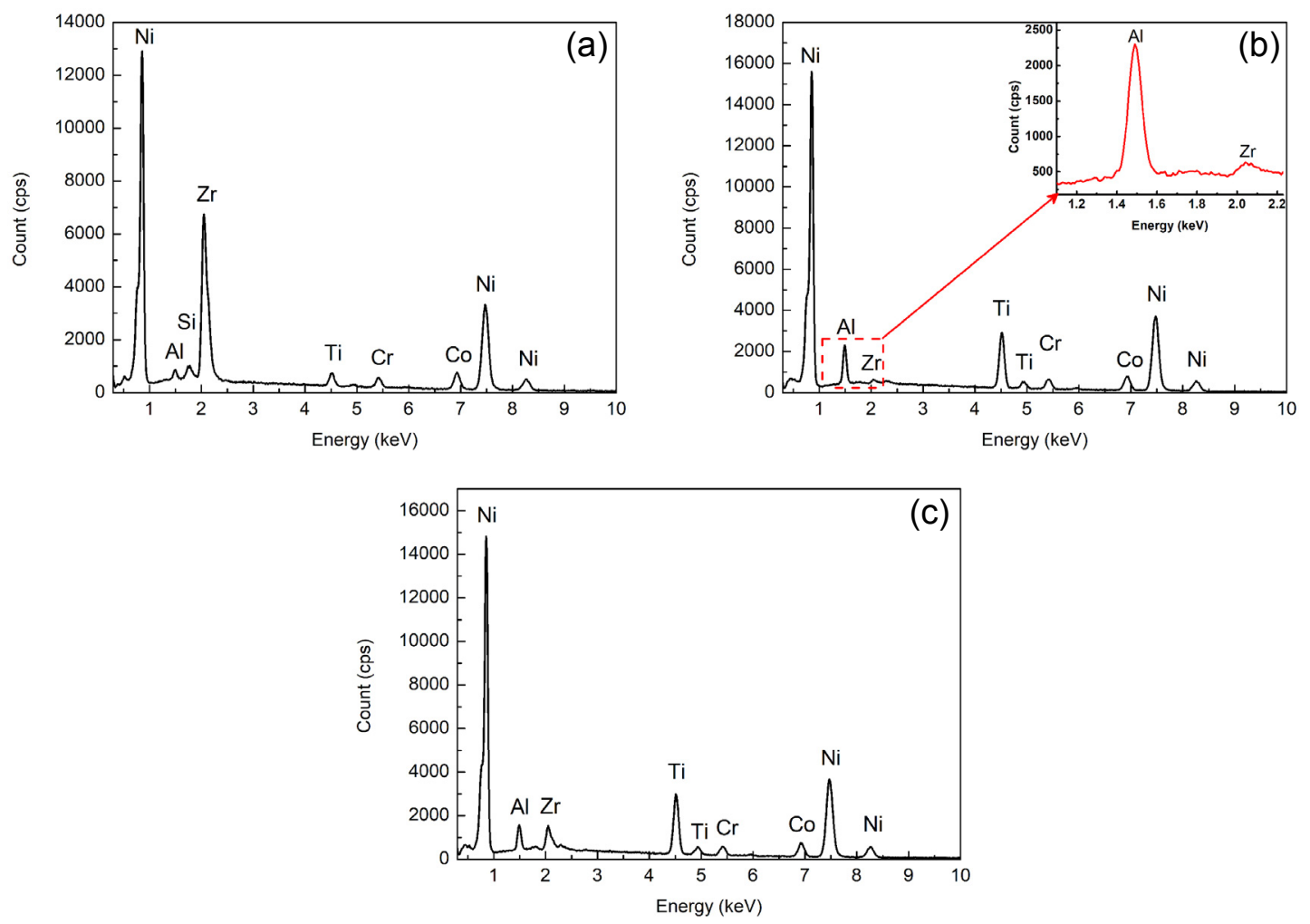

Fig. 5: EDS spectra of Zr-rich phase (a), eutectic $\mathrm{Y}^{\prime}$ (b) and $\eta$ phase (c)
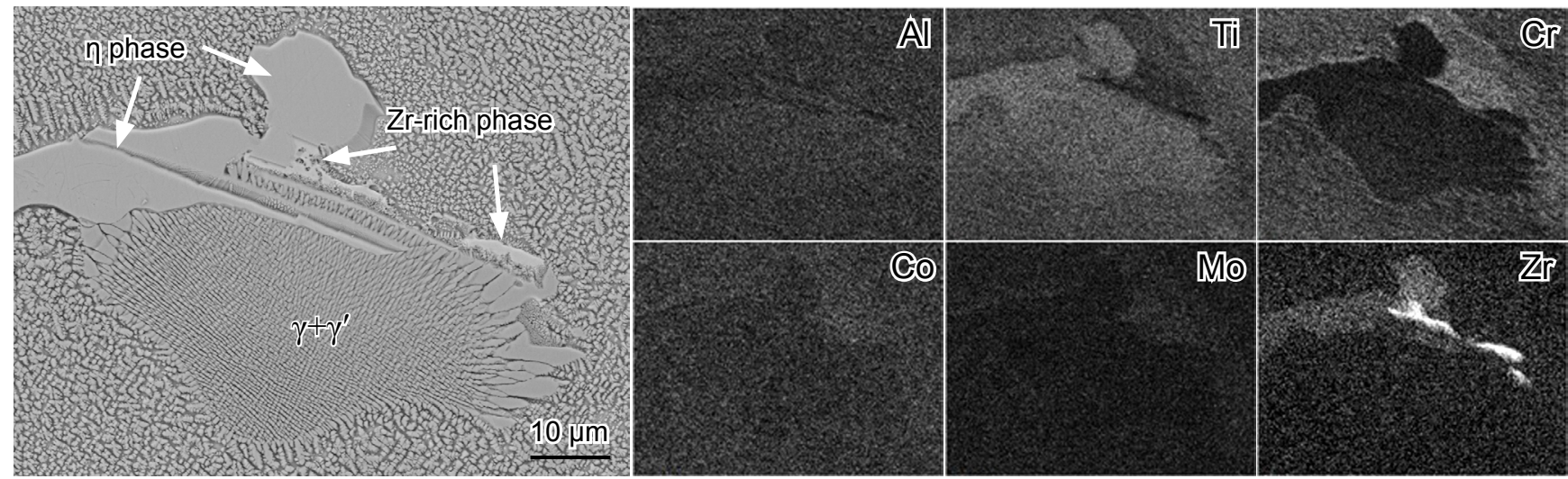

Fig. 6: Elemental distribution in interdendritic region of solidified DTA sample of high-Zr alloy with $0.150 \mathrm{wt} . \% \mathrm{Zr}$
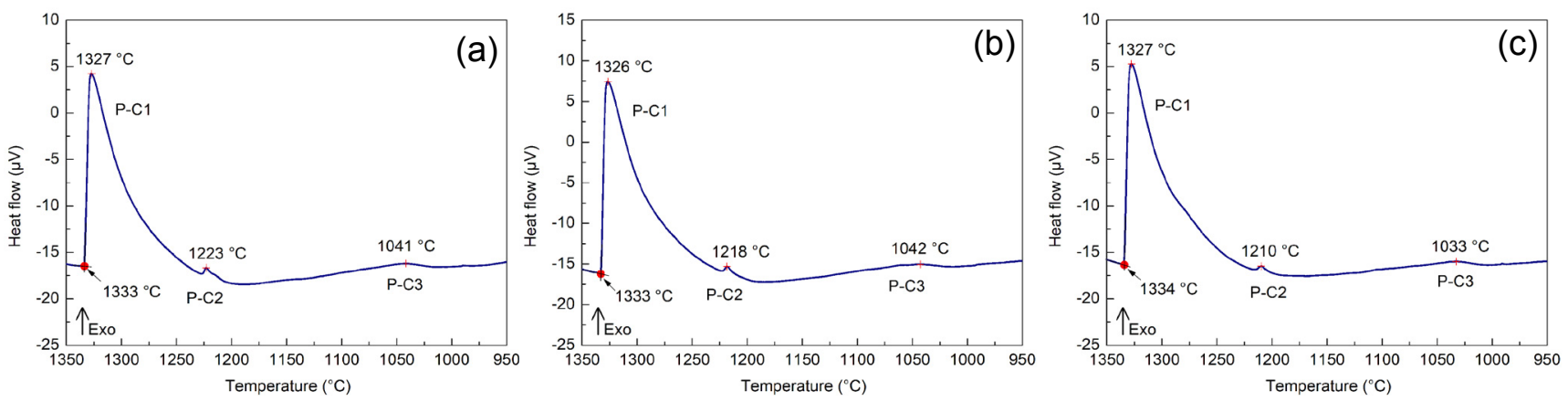

Fig. 7: DTA cooling curves of undoped alloy with $<0.0006 w t . \% \mathrm{Zr}$ (a), middle- $\mathrm{Zr}$ alloy with $0.043 w \mathrm{wt} \% \mathrm{Zr}$ (b) and high- $\mathrm{Zr}$ alloy with $0.150 \mathrm{wt} . \% \mathrm{Zr}(\mathrm{c})$, cooled from super-solidus temperature with cooling rate of $10^{\circ} \mathrm{C} \cdot \mathrm{min}^{-1}$

delays the precipitation of eutectic $\left(\gamma+\gamma^{\prime}\right)$ and $\eta$ phase. Since the solidification of Ni-based superalloys always terminates with the formation of nonequilibrium eutectics, the difference between initial temperatures of $\mathrm{P}-\mathrm{C} 1$ and $\mathrm{P}-\mathrm{C} 2$ is defined as the formation interval of $\gamma$ dendrites. Besides, the width of $\mathrm{P}-\mathrm{C} 2$ is defined as the formation interval of [eutectic $\left(\gamma+\gamma^{\prime}\right)+\eta$ ]. Clearly, the formation interval of $\gamma$ dendrites is enlarged by the $\mathrm{Zr}$ addition, but that of [eutectic $\left.\left(\gamma+\gamma^{\prime}\right)+\eta\right]$ is little influenced. 
Table 2: Summary of solidification reaction temperatures $\left({ }^{\circ} \mathrm{C}\right)$ in DTA curves

$\begin{array}{ccccccc}\text { Alloy } & \text { P-C1 initial } & \text { P-C1 peak } & \text { P-C2 initial } & \text { P-C2 peak } & \text { P-C2 final } & \text { P-C3 peak } \\ \text { Undoped } & 1,333 & 1,327 & 1,226 & 1,223 & 1,198 & 1,041 \\ \text { Middle-Zr } & 1,333 & 1,326 & 1,223 & 1,218 & 1,194 & 1,042 \\ \text { High-Zr } & 1,334 & 1,327 & 1,215 & 1,210 & 1,187 & 1,033\end{array}$

\subsection{Segregation behaviors of solidified DTA samples}

Figure 8 presents average compositions of the dendrite core, segregated region, eutectic $\left(\gamma+\gamma^{\prime}\right)$ and $\eta$ phase in the undoped alloy, middle-Zr alloy and high-Zr alloy DTA samples. It is easily concluded that $\mathrm{Ti}$ and $\mathrm{Al}$ exhibits positive segregation, while $\mathrm{Cr}, \mathrm{Co}$ and Mo shows negative segregation. The segregation degrees of $\mathrm{Ti}$ and $\mathrm{Cr}$ are obviously stronger than those of the other elements. It is also seen that $\mathrm{Zr}$ has little influence on the average composition of dendrite core and eutectic $\left(\gamma+\gamma^{\prime}\right)$ [Fig. 8(a) and Fig. 8(c)], but has obvious effect on those of the segregated region and $\eta$ phase [Fig. 8(b) and Fig. 8(d)]. For the segregated region, increase in $\mathrm{Zr}$ addition linearly decreases the average concentration of $\mathrm{Ti}$ and slightly increases that of $\mathrm{Cr}$, but has little influence on those of $\mathrm{Al}, \mathrm{Co}$ and Mo [Fig. 8(b)]. For the $\eta$ phase, increase in $\mathrm{Zr}$ not only significantly decreases the average concentration of Ti but also markedly decreases that of Co and slightly decreases that of $\mathrm{Cr}$ [Fig. 8(d)]. Since $\mathrm{Zr}$ dissolves slightly in the eutectic $\left(\gamma+\gamma^{\prime}\right)$ and hardly in the matrix (Fig. 5 and Fig. 6), the average concentrations of $\mathrm{Zr}$ in them were excluded to keep the reliability of measurement results.

\subsection{Microstructures of as-quenched samples}

To further investigate the influential mechanism of $\mathrm{Zr}$ on formation of the nonequilibrium solidification phases, a quenching test was performed to preserve the high temperature microstructures of undoped and high-Zr alloys before formation of these phases. Figure 9 presents the microstructures of the undoped alloy [Fig. 9(a)] and high-Zr alloy [Fig. 9(b)] soaked at $1,400{ }^{\circ} \mathrm{C}$ for $5 \mathrm{~min}$, cooled to $1,250{ }^{\circ} \mathrm{C}$ at $10^{\circ} \mathrm{C} \cdot \mathrm{min}^{-1}$ and soaked for another $3 \mathrm{~min}$, and finally quenched in water. It can be concluded from the as-quenched microstructures that before formation of the nonequilibrium phases the size and morphology of liquid pools in the high-Zr alloy are quite different from those in the undoped alloy. Specifically, the liquid pools in the (a)

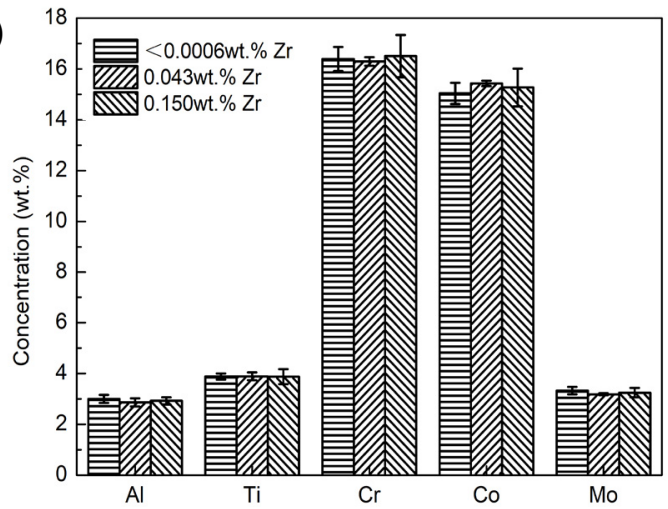

(c)

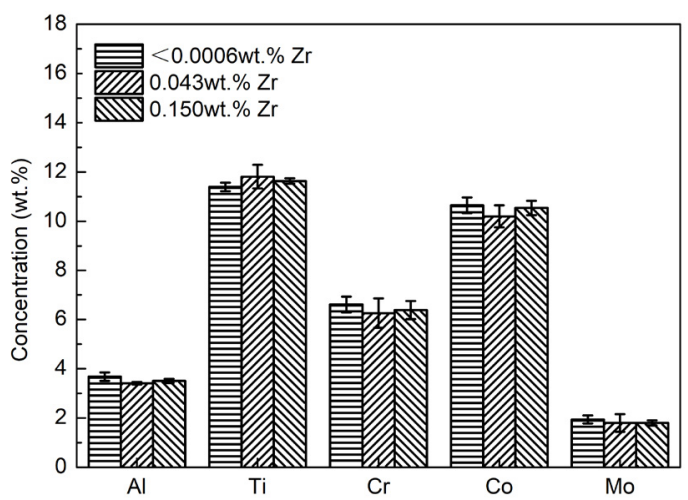

(b)

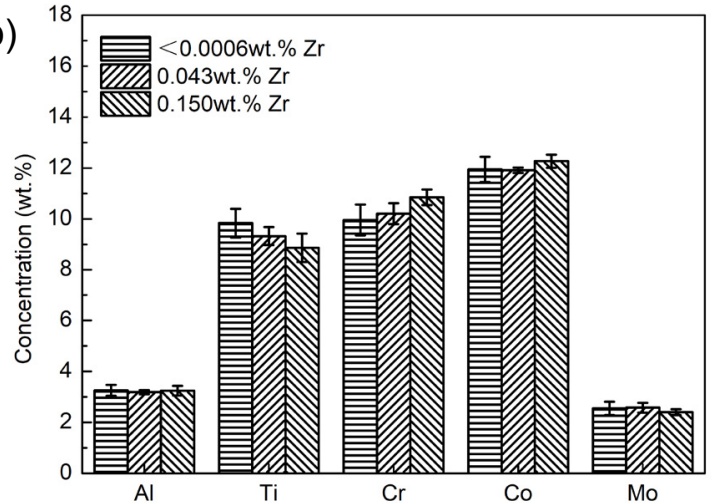

(d)

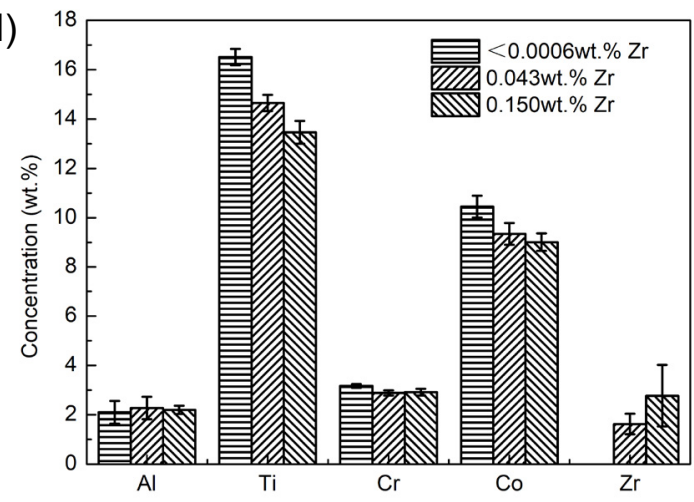

Fig. 8: Average compositions of dendrite core (a), segregated region (b), eutectic $\left(\gamma+\gamma^{\prime}\right)$ (c) and $\eta$ phase (d) in solidified DTA samples of undoped alloy with $<0.0006 w t . \% \mathrm{Zr}$, middle-Zr alloy with $0.043 w t . \% \mathrm{Zr}$ and high-Zr alloy with $0.150 \mathrm{wt}$. $\% \mathrm{Zr}$ 

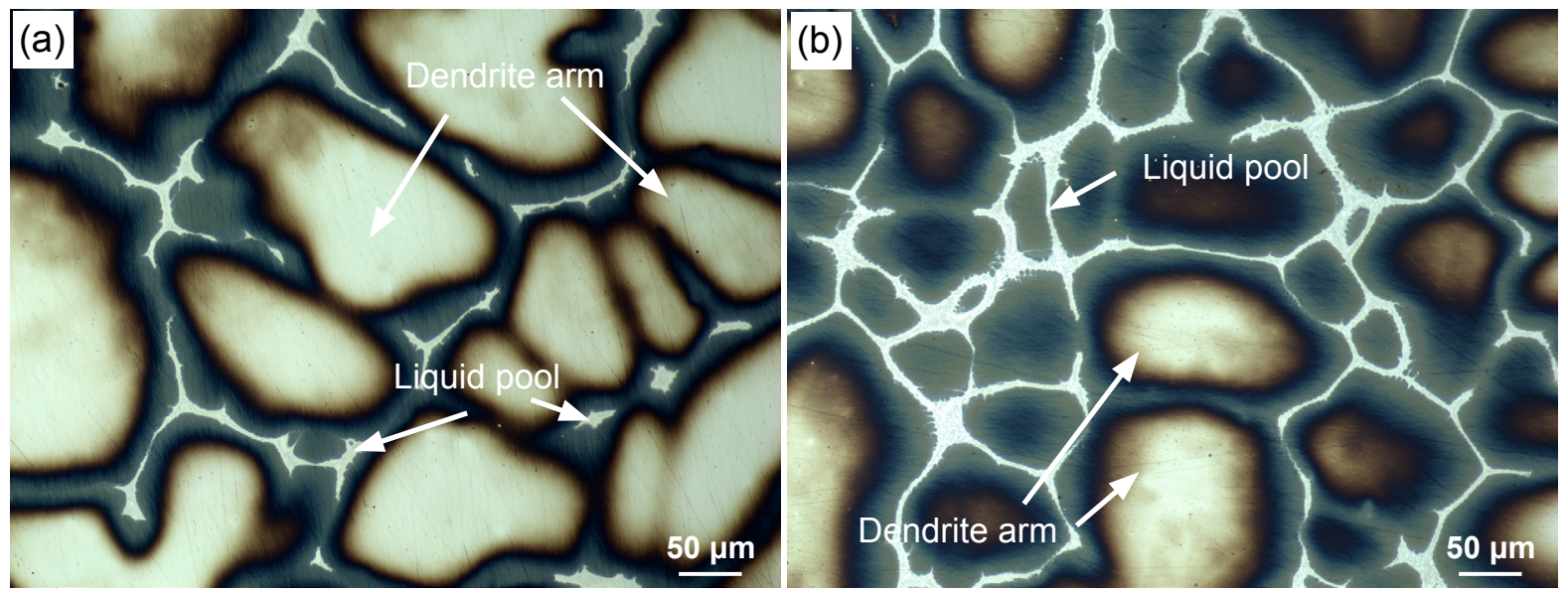

Fig. 9: Dendritic structures of undoped alloy with $<0.0006 \mathrm{wt} . \% \mathrm{Zr}$ (a) and high-Zr alloy with $0.150 \mathrm{wt} . \% \mathrm{Zr}$ (b) soaked at $1,400{ }^{\circ} \mathrm{C}$ for $5 \mathrm{~min}$, cooled to $1,250^{\circ} \mathrm{C}$ at $10^{\circ} \mathrm{C} \cdot \mathrm{min}^{-1}$ and soaked for $3 \mathrm{~min}$, then quenched in water

undoped alloy mainly exist in the form of isolated pockets, while those in the high-Zr alloy mainly present as continuous thin films. The average length, width and area fraction of the liquid pools in the high-Zr alloy are markedly greater than those in the undoped alloy. The quantitative analysis results are shown in Table 3. Owing to the existence of solute concentration gradient between the dendrite core and edge of the liquid pools, the color of dendrite arms becomes darker towards the liquid pools ${ }^{[5]}$.

Table 3: Average length, width and area fraction of liquid pools in as-quenched samples of undoped and high-Zr alloys

$\begin{array}{cccc}\text { Alloy } & \text { Average length }(\mu \mathrm{m}) & \text { Average width }(\mu \mathrm{m}) & \text { Average area fraction }(\%) \\ \text { Undoped } & 71.27 \pm 57.75 & 6.10 \pm 4.68 & 3.15 \% \pm 0.39 \\ \text { High-Zr } & 205.14 \pm 166.11 & 7.02 \pm 5.67 & 7.03 \% \pm 0.51\end{array}$

\subsection{Segregation behaviors of as-quenched samples}

As shown in Fig. 10, Zr has little influence on the average composition of dendrite core but has apparent influence on that of the segregated region (the matrix at the edge of liquid pools). That is, the $\mathrm{Zr}$ addition obviously reduces the average concentration of $\mathrm{Ti}$ and increases the average concentration of $\mathrm{Cr}$ in the segregated region of as-quenched samples. Furthermore, the EDS mapping conducted in the liquid pools of the high-Zr alloy as-quenched sample (Fig. 11) suggests that $\mathrm{Zr}$ is strongly enriched in residual liquid before the formation of nonequilibrium phases, which eventually leads to the distribution characteristic of $\mathrm{Zr}$ in the solidified samples (Fig. 6).

\section{Discussion}

Several studies have reported that a certain amount of $\mathrm{Zr}$ addition can significantly promotes the precipitation of eutectic $\left(\gamma+\gamma^{\prime}\right)$ at the
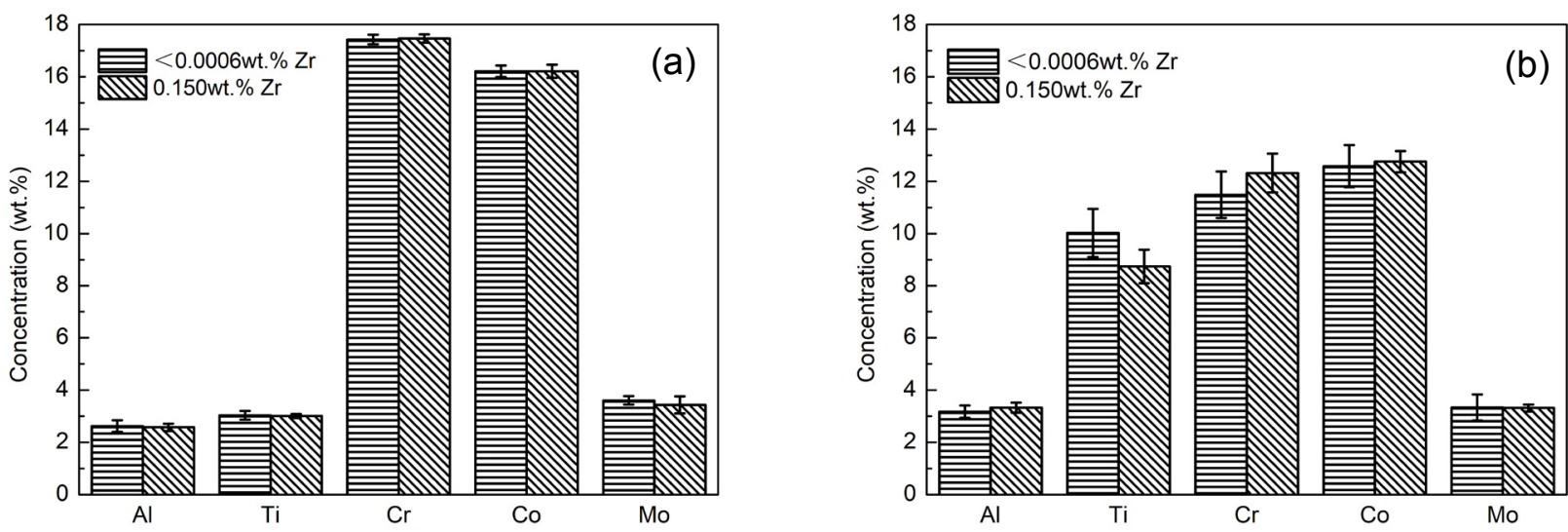

Fig. 10: Average compositions of dendrite core (a) and segregated region (b) in as-quenched samples of undoped alloy with $<0.0006 \mathrm{wt} . \% \mathrm{Zr}$ and high-Zr alloy with $0.150 \mathrm{wt} . \% \mathrm{Zr}$ 
final solidification stage of Ni-based superalloys ${ }^{[22,30,36]}$. This study has excluded the interferences of $\mathrm{C}$ and $\mathrm{B}$ and found that $\mathrm{Zr}$ not only increases the precipitation of eutectic $\left(\gamma+\gamma^{\prime}\right)$ but also increases the precipitation of $\eta$ phase (Fig. 3).

The phenomenon that $\mathrm{Zr}$ obviously increases the average area fraction, length and width of the liquid pools (Fig. 9 and Table 3) suggests that the alloy solidification is markedly retarded by the $\mathrm{Zr}$ addition, which is in accordance with the view proposed by Qi et $\mathrm{al}^{[30]}$. But unlike their study, the DTA analysis was conducted on solidification behaviors of the alloys with different $\mathrm{Zr}$ contents in this study and hence more vital information can be obtained. Based on the DTA cooling curves, the formation interval of $\gamma$ dendrites is markedly enlarged by the $\mathrm{Zr}$ addition (Fig. 7), which also reflects the hindering effect of $\mathrm{Zr}$ on solidification. In other words, the result of the quenching test is in agreement with that of the DTA analysis. But why the Zr addition retards the alloy solidification? The theory of crystal growth suggests that the growth velocity $V$ can be expressed as $V=\delta\left(R_{\mathrm{s}}-R_{1}\right)$, where $\delta$ is a typical inter-atomic spacing, $R_{\mathrm{s}}$ is the transition rate of atoms from liquid to solid state, and $R_{1}$ is the transition rate from solid to liquid state ${ }^{[37,38]}$. The enrichment of $\mathrm{Zr}$ in residual liquid is observed (Fig. 11), which confirms that $\mathrm{Zr}$ is strongly expelled into the liquid during solidification. This agrees with previous research results and the reason is mainly related to the large atomic radius of $\mathrm{Zr}$ and its low solubility in $\gamma$ matrix ${ }^{[39,40,41]}$. The strong accumulation of large $\mathrm{Zr}$ atoms in the residual liquid can hinder the diffusion of other elements, which reduces both the $R_{\mathrm{s}}$ and $R_{1}$ obviously. It is presumed that the percentage of decrease in $R_{\mathrm{s}}$ is similar to that in $R_{\mathrm{l}}$, and then the growth velocity $V$ would be reduced by the same percentage. This leads to the decrease in $\gamma$ dendrite growth rate, i.e., the retard of solidification. Besides, it has been reported that if $\gamma_{\mathrm{gb}}-2 \gamma_{\mathrm{sl}}<0$, the solid/liquid interfaces will coalesce instantly as soon as their distance reaches the atom level, but if $\gamma_{\mathrm{gb}}-2 \gamma_{\mathrm{sl}}>0$, extra undercooling is required to solidify, where $\gamma_{\mathrm{gb}}$ is the grain boundary energy and $\gamma_{\mathrm{sl}}$ is the solid/liquid surface energy ${ }^{[39,42]}$. Since the $\gamma_{\mathrm{sl}}$ can be obviously reduced by absorbing certain solute elements at the interface ${ }^{[43,44]}$, it is reasonable to conclude that the enrichment of $\mathrm{Zr}$ in residual liquids could reduce the solid/liquid surface energy $\gamma_{\mathrm{sl}}$ and hence retards the solidification ${ }^{[10]}$.

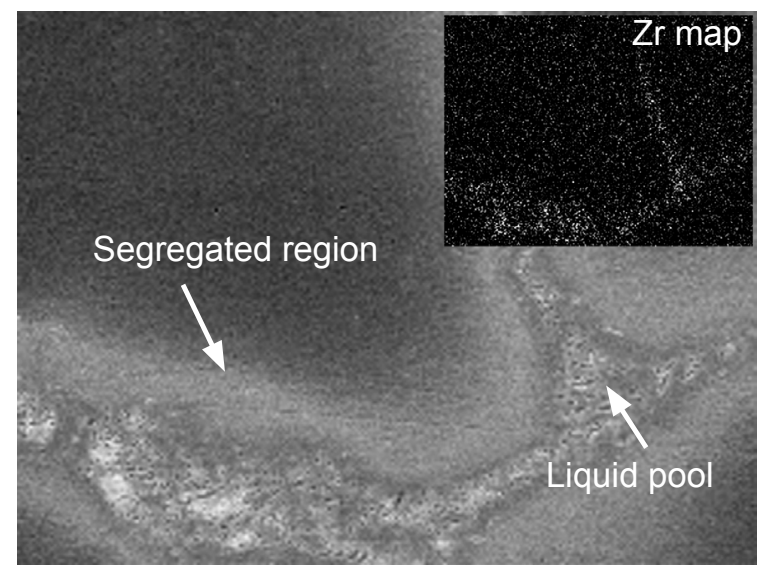

Fig. 11: Distribution of $\mathrm{Zr}$ in liquid pool of high-Zr alloy as-quenched sample
It has been discovered that the eutectic $\left(\gamma+\gamma^{\prime}\right)$ formation actually starts with a peritectic reaction of $(\mathrm{L}+\gamma) \rightarrow \gamma^{\prime}$ from $\gamma$ dendrites surrounding the liquid pools and grows with a eutectic reaction of $\mathrm{L} \rightarrow\left(\gamma+\gamma^{\prime}\right)$ into the liquid, while the $\eta$ phase forms directly from the residual liquid ${ }^{[35]}$. Based on the EDS analysis (Figs. 5 and 8), the eutectic $\left(\gamma+\gamma^{\prime}\right)$ is mainly composed of $\mathrm{Ni}$, Ti and $\mathrm{Al}$, and the $\eta$ phase is mainly composed of $\mathrm{Ni}$ and $\mathrm{Ti}$. Since $\mathrm{Al}$ only exhibits slight segregation, the precipitations of both phases are mainly related to the segregation of $\mathrm{Ti}$. The Ti/Al ratio of the $\eta$ phase is obviously higher than that of the eutectic $\left(\gamma+\gamma^{\prime}\right)$. When the Ti/Al ratio is relatively low, the accumulation of $\mathrm{Ti}$ in the liquid favors the eutectic $\left(\gamma+\gamma^{\prime}\right)$ precipitation. But when the Ti/Al ratio is increased to a certain value, the $\eta$ phase will be formed ${ }^{[34]}$. The inevitable composition inhomogeneity in solidified alloys naturally leads to the uneven precipitation of these two phases, i.e., in some interdendritic areas both the eutectic $\left(\gamma+\gamma^{\prime}\right)$ and $\eta$ phase are formed, but in the other areas individual eutectic $\left(\gamma+\gamma^{\prime}\right)$ or $\eta$ is formed (Fig. 4).

The retard of solidification naturally increases the residual liquid fraction and slows down the accumulation of the eutectic $\left(\gamma+\gamma^{\prime}\right)$ and $\eta$ forming element Ti into the liquid, which in turn postpones these two phases precipitation ${ }^{[5]}$. Thus, the higher the $\mathrm{Zr}$ content, the lower the initial temperature of [eutectic $\left.\left(\gamma+\gamma^{\prime}\right)+\eta\right]$ precipitation (Fig. 7). The lower initial precipitation temperature would cause greater undercooling, which reduces the nucleation energy and promotes their nucleation. In this case, when the eutectic $\left(\gamma+\gamma^{\prime}\right)$ and $\eta$ phase start to nucleate, the residual liquid fraction of the higher $\mathrm{Zr}$ content alloy should be greater than that of the lower $\mathrm{Zr}$ content alloy. Once nucleated, they will grow more freely in the larger liquid pools of the higher $\mathrm{Zr}$ content alloy. This is one of the reasons that the $\mathrm{Zr}$ addition increases the eutectic $\left(\gamma+\gamma^{\prime}\right)$ and $\eta$ phase precipitation. Besides, it has been found in this study that $\mathrm{Zr}$ dissolves slightly in the eutectic $\gamma^{\prime}$ and significantly in the $\eta$ phase (Fig. 5 and Fig. 6), which indicates that $\mathrm{Zr}$ can act as a forming element for the eutectic $\left(\gamma+\gamma^{\prime}\right)$ and $\eta$ phase. Inevitably, the dissolution of $\mathrm{Zr}$ in the eutectic $\left(\gamma+\gamma^{\prime}\right)$ would occupy positions of the other elements in their lattices. Thus, the significant dissolution of $\mathrm{Zr}$ in the $\eta$ phase obviously lowers the critical Ti concentration for its precipitation [Fig. 8(d)]. But the slight dissolution of $\mathrm{Zr}$ in the eutectic $\gamma^{\prime}$ has no obvious influence on concentrations of the other elements in the eutectic $\left(\gamma+\gamma^{\prime}\right)$ [Fig. 8(c)]. The increase in amounts of forming elements and decrease in required concentrations for the forming elements are naturally favourable to the nucleation and growth of the precipitates. In general, the dissolution of $\mathrm{Zr}$ in the eutectic $\gamma^{\prime}$ and $\eta$ phase also contributes to the increase in eutectic $\left(\gamma+\gamma^{\prime}\right)$ and $\eta$ formation, especially the $\eta$ phase. Although $\mathrm{Zr}$ can be partially dissolved in the eutectic $\gamma^{\prime}$ and $\eta$ phase, a $\mathrm{Zr}$ addition of $0.043 \mathrm{wt} . \%$ has reached beyond the limit of solubility and hence causes formation of the Zr-rich phase in the final liquid ahead of the former precipitations. And the increase in $\mathrm{Zr}$ content naturally increases the amount of the $\mathrm{Zr}$-rich phase. However, the $\mathrm{Zr}$-rich phase is a low-melting point phase and its existence may bring about incipient melting during hot working and homogenization treatment of ingots which 
causes premature failure during service of the components ${ }^{[36,45]}$ Based on the above analysis, before precipitation of these nonequilibrium phases, the residual liquid fraction in the higher $\mathrm{Zr}$ content alloy must be greater than that in the lower $\mathrm{Zr}$ content alloy. Thus, the chemical gradient of solute elements between the dendrite core and segregated region of the higher $\mathrm{Zr}$ content alloy should be smaller, i.e., the concentration of positive segregation element $\mathrm{Ti}$ in the segregated region decreases but that of the negative segregation element $\mathrm{Cr}$ in this region increases with increasing the $\mathrm{Zr}$ addition [Fig. 8(b) and Fig. 10(b)].

$\mathrm{Zr}$ is usually added in Ni-based superalloys to improve the mechanical properties ${ }^{[45,46]}$, because $\mathrm{Zr}$ can enhance grain boundary strength and counteract impurity $\mathrm{S}$ and $\mathrm{O}{ }^{[30,44,47]}$. However, our present study has confirmed that excess $\mathrm{Zr}$ doping significantly promoted the formation of harmful eutectic $\left(\gamma+\gamma^{\prime}\right)$, $\eta$ and Zr-rich phases. This detrimental effect should also be considered in $\mathrm{Zr}$ microalloying process.

\section{Conclusions}

(1) The increase in $\mathrm{Zr}$ addition significantly promotes the formation of eutectic $\left(\gamma+\gamma^{\prime}\right), \eta$ phase and $\mathrm{Zr}$-rich phase at the final solidification stage.

(2) As the solidification proceeds, $\mathrm{Zr}$ is continuously rejected into liquid phase and the final liquid becomes strongly enriched in $\mathrm{Zr}$. This in turn leads to the Zr-rich phase formation, strong segregation of $\mathrm{Zr}$ to the $\eta$ phase and slight segregation of $\mathrm{Zr}$ to the eutectic $\gamma^{\prime}$.

(3) $\mathrm{Zr}$ markedly retards the alloy solidification, as is verified by the evidence that $\mathrm{Zr}$ enlarges the forming range of $\gamma$ dendrites and increases the average area fraction, width and length of liquid pools.

(4) $\mathrm{Zr}$ promotes the eutectic $\left(\gamma+\gamma^{\prime}\right)$ and $\eta$ phase precipitation mainly for two reasons: (a) the retard of solidification significantly increases the residual liquid fraction and undercooling. (b) $\mathrm{Zr}$ can act as a forming element for the eutectic $\left(\gamma+\gamma^{\prime}\right)$ and $\eta$ phase, and the obvious dissolution of $\mathrm{Zr}$ in the $\eta$ phase markedly decreases the critical Ti concentration for its precipitation.

\section{Acknowledgement}

This work was financially supported by the National Natural Science Foundation of China (Grant No. 51904146).

\section{References}

[1] Reed R C. The superalloys: Fundamentals and applications. New York: Cambridge University Press, 2008.

[2] Pu Y L, Kou S Z, Zhang Z D, et al. Effects of returns on composition, microstructure and mechanical properties of GH4169 superalloy. China Foundry, 2017, 14(4): 244-250.

[3] Kim S E, Jackson M P, Reed R C, et al. Quantification of the minor precipitates in UDIMET ${ }^{\mathrm{TM}}$ alloy 720 (Li) using electrolytic extraction and $X$-ray diffraction. Materials Science and Engineering: A, 1998, 245(2): 225-232.
[4] Monajati H, Taheri A K, Jahazi M, et al. Deformation characteristics of isothermally forged UDIMET 720 nickel-base superalloy. Metallurgical and Materials Transactions A, 2005, 36: 895-905.

[5] Zhao G D, Yu LX, Yang G L, et al. The role of boron in modifying the solidification and microstructure of nickel-base alloy U720Li. Journal of Alloys and Compounds, 2016, 686: 194-203.

[6] Chang L T, Jin H, Sun W R. Solidification behavior of Ni-base superalloy udimet $720 \mathrm{Li}$. Journal of Alloys and Compounds, 2015, 653: 266-270.

[7] Keefe P W, Mancuso S O, Maurer G E. Effects of heat treatment and chemistry on the long-term phase stability of a high strength nickel-based superalloy. Superalloys, 1992: 487-496.

[8] Helm D, Roder O. Influence of long term exposure in air on microstructure, surface stability and mechanical properties of udimet 720 Li. Superalloys, 2000: 487-493.

[9] Zhao G D, Liu F, Zang X M, et al. Microstructure and hot ductility behavior of Ni-based superalloy U720Li with boron addition. Rare Metals, 2021, 40(5): 1145-1154.

[10] Zhang J, Singer R F. Effect of Zr and B on castability of Ni-based superalloy IN792. Metallurgical and Materials Transactions A, 2004, 35: 1337-1342.

[11] Sun W R, Zhao G D, Yu L X, et al. Homogenization process of superalloy U720Li, CN: ZL 201610459197.4, 2016. (In Chinese)

[12] Zhao G D, Zang X M, Qi F. Effect of boron on isothermal oxidation behavior of a nickel-base superalloy with high $\mathrm{Al}$ and Ti contents. Journal of Alloys and Compounds, 2020, 846: 156490.

[13] Couturier R, Burlet $H$, Terzi S, et al. Process development and mechanical properties of alloy U720Li for high temperature turbine disks. In: Proc. International Symposium on Superalloys, 2004: 351-359. doi:10.7449/2004/Superalloys_2004_351_359.

[14] Fecht H, Furrer D. Processing of nickel-base superalloys for turbine engine disc applications. Advanced Engineering Materials, 2000, 2(12): 777-787.

[15] Seo S M, Lee J H, Yoo Y S, et al. A comparative study of the $y / y^{\prime}$ eutectic evolution during the solidification of Ni-base superalloys. Metallurgical and Materials Transactions A, 2011, 42: 3150-3159.

[16] Zhang $X Y$, Liu L, Huang $T W$, et al. Effect of solidification parameters on the segregation and $Y / Y^{\prime}$ eutectic evolution in Ni-based single crystal superalloy DD6. Rare Metal Materials and Engineering, 2013, 42: 2547-2552.

[17] Liu L, Huang T W, Zhang J, et al. Microstructure and stress rupture properties of single crystal superalloy CMSX-2 under high thermal gradient directional solidification. Materials Letters, 2007, 61(1): 227-230.

[18] Zhang H, Pei Y, Li S, et al. Effect of process parameters on microstructures and properties of DZ125 superalloy solidified by LMC. Materials Research Innovations, 2014, 18: 385-389.

[19] Li Y M, Liu H J, Liu J, et al. Effect of Zr addition on precipitates in K4169 superalloy. China Foundry, 2012, 9(1): 6-10.

[20] Garosshen T J, Tillman T D, McCarthy G P. Effects of B, C, and $\mathrm{Zr}$ on the structure and properties of a P/M nickel-base superalloy. Metallurgical Transactions A, 1987, 18: 69-77.

[21] Huang $\mathrm{H} \mathrm{E}, \mathrm{Koo} \mathrm{C} \mathrm{H}$. Effect of zirconium on microstructure and mechanical properties of cast fine-grain CM 247 LC superalloy. Materials Transactions, 2004, 45(2): 554-561.

[22] Zhou P J, Yu J J, Sun X F, et al. Roles of $Z r$ and $Y$ in cast microstructure of M951 nickel-based superalloy. Transactions of Nonferrous Metals Society of China, 2012, 22: 1594-1598.

[23] Wei C N, Bor H Y, Chang L. The effects of carbon content on the microstructure and elevated temperature tensile strength of a nickel-base superalloy. Materials Science and Engineering: A, 2010, 527: 3741-3747. 
[24] Al-Jarba K A, Fuchs G E. Effect of carbon additions on the ascast microstructure and defect formation of a single crystal Nibased superalloy. Materials Science and Engineering: A, 2004, 373(1-2): 255-267.

[25] Liu L R, Jin T, Zhao N R, et al. Effect of carbon additions on the microstructure in a Ni-base single crystal superalloy. Materials Letters, 2004, 58(17-18): 2290-2294.

[26] Heydari D, Shahkaram F A, Bakhshi A, et al. Hot tearing in polycrystalline Ni-based IN738LC superalloy: Influence of $\mathrm{Zr}$ content. Journal of Materials Processing Technology, 2014, 214(3): 681-687.

[27] Yan B C, Zhang J, Lou L H. Effect of boron additions on the microstructure and transverse properties of a directionally solidified superalloy. Materials Science and Engineering: A, 2008, 474(1-2): 39-47.

[28] Hu Q, Liu L, Zhao X B, et al. Effect of carbon and boron additions on segregation behavior of directionally solidified nickel-base superalloys with rhenium. Transactions of Nonferrous Metals Society of China, 2013, 23(11): 3257-3264.

[29] Zhao G D, Zang X M, Sun W R. Role of carbon in modifying solidification and microstructure of a Ni-based superalloy with high $\mathrm{Al}$ and Ti contents. Journal of Iron and Steel Research International, 2021, 28: 98-110.

[30] Qi F, Yu L X, Zhao G D, et al. Effect of Zr on solidification segregation behavior of $\mathrm{K} 417 \mathrm{G}$ alloy and its anomalous effect during rapid cooling process. Journal of Alloys and Compounds, 2020, 835(6): 155243.

[31] Tsai $Y L$, Wang S F, Bor H Y, et al. Effects of $Z r$ addition on the microstructure and mechanical behavior of a fine-grained nickel-based superalloy at elevated temperatures. Materials Science and Engineering: A, 2014, 607: 294-301.

[32] Voort G. Metallography: Principles and practice. McGraw-Hill, 1984.

[33] Hobbs R A, Tin S, Rae C M F. A castability model based on elemental solid-liquid partitioning in advanced nickel-base single-crystal superalloys. Materials Science and Engineering: A, 2005, 36: 2761-2773.

[34] Zhao G D, Yu L X, Qi F, et al. The minor precipitation at the final stage of U720Li solidification. Acta Metallurgica Sinica (English Letters), 2016, 29: 518-526.
[35] Zhao G D, Yang G L, Liu F, et al. Transformation mechanism of $\left(\gamma^{+} \mathrm{Y}^{\prime}\right)$ and the effect of cooling rate on the final solidification of U720Li alloy. Acta Metallurgica Sinica, 2017, 30: 887-894.

[36] Mostafaei M, Abbasi S M. Influence of Zr content on the incipient melting behavior and stress-rupture life of CM247 LC nickel base superalloy. Journal of Alloys and Compounds, 2015, 648: 1031-1037.

[37] Herlach D M. Non-equilibrium solidification of undercooled metallic metls. Materials Science and Engineering: Reports, 1994,12(4-5): 177-272.

[38] Christian J W. The theory of transformations in metals and alloys. 1965.

[39] Grodzki J, Hartmann N, Rettig R, et al. Effect of B, Zr, and C on hot tearing of a directionally solidified Nickel-based superalloy. Metallurgical and Materials Transactions A, 2016, 47(6): 29142926.

[40] Holt R T, Wallace W. Impurities and trace elements in nickelbase superalloys. Int. Met. Rev., 1976, 21: 1-24.

[41] Doherty J E, Kea B H, Giamei A F. On the origin of the ductility enhancement in Hf-doped Mar-M200. The Journal of the Minerals, Metals and Materials Society, 1971, 23(11): 59-62.

[42] Rappaz M, Jacot A, Boettinger W J. Last-stage solidification of alloys: Theoretical model of dendrite-arm and grain coalescence. Metallurgical and Materials Transactions A, 2003, 34: 467-479.

[43] Keene J B. Review of data for the surface tension of pure metals. Metallurgical Reviews, 1993, 38: 157-192.

[44] McLean D. Grain boundaries in metals. Oxford: Clarendon Press, 1957.

[45] Gozlan E, Bamberger M, Dirnfeld S F, et al. Role of zirconium in the phase formation at the interdendritic zone in nickelbased superalloys. Journal of Materials Science, 1992, 27: 3869-3875.

[46] Decker R F, Freeman J W. The mechanism of beneficial effects of boron and zirconium on creep properties of a complex heatresistant alloy. Technical Report Archive and Image Library, 1960, 218: 277-285.

[47] Seah M P. Adsorption-induced interface decohesion. Acta Metallurgica, 1980, 28(7): 955-962. 